\title{
Progress in Primary Aldosteronism 2019: New Players on the Block?
}

(c) (1) $\odot$

\author{
Authors \\ Martin Reincke, Felix Beuschlein, Tracy Ann Williams
}

\author{
Affiliation \\ Medizinische Klinik und Poliklinik IV, Klinikum der Universität \\ München, Munich, Germany \\ received $\quad 07.04 .2020$ \\ accepted $\quad 08.04 .2020$ \\ Bibliography \\ Horm Metab Res 2020; 52: 345-346 \\ DOI 10.1055/a-1156-9926 \\ ISSN $\quad 0018-5043$ \\ (c) 2020. The Author(s) \\ This is an open access article published by Thieme under the terms of the \\ Creative Commons Attribution-NonDerivative-NonCommercial-License, \\ permitting copying and reproduction so long as the original work is given \\ appropriate credit. Contents may not be used for commercial purpose, or \\ adapted, remixed, transformed or built upon. (https://creativecommons. \\ org/licenses/by-nc-nd/4.0/) \\ Georg Thieme Verlag KG, Rüdigerstraße 14, \\ 70469 Stuttgart, Germany
}

\author{
Correspondence \\ Martin Reincke \\ Medizinische Klinik und Poliklinik IV, Klinikum der Universi- \\ tät München, LMU München \\ Ziemssenstraße 1 \\ 80336 Munich \\ Germany \\ Tel.: +498951602100, \\ Fax: + 498951604428 \\ martin.reincke@med.uni-muenchen.de
}

Primary aldosteronism (PA) is characterized by hypertension caused by inappropriately high adrenal aldosterone secretion, consecutively low plasma renin, and an elevated aldosterone to renin ratio. It is nowadays the universally accepted main cause of endocrine hypertension. According to the most recent epidemiological data, $\mathrm{PA}$ is present in $5.8 \%$ of unselected hypertensives in primary care, $6-12 \%$ of hypertensives treated in hypertension centers, and up to $30 \%$ in subjects with resistant hypertension [1]. Despite this high prevalence, a recent survey demonstrated that screening for PA is not universally followed. Renin and aldosterone measurements, the basis for PA screening, are currently performed by only $7 \%$ of general practitioners in Italy and $8 \%$ in Germany [2]. Accordingly, the prevalence of PA was low with $1 \%$ among hypertensives in Italy and $2 \%$ in Germany. In a retrospective cohort study of 4660 patients with resistant hypertension in California the screening rate for PA was $2.1 \%$ [3]. Based on these data, it is clear that we still miss the majority of PA cases, despite advances in diagnosis and therapy.

Early diagnosis of PA would definitely save many lives: morbidity of PA subjects compared with matched hypertensives is substantially increased at the time of diagnosis [4]. Despite this unfavorable baseline situation, the long-term prognosis is excellent with specific treatment measures, unilateral adrenalectomy for a unilateral adenoma, and mineralocorticoid antagonist treatment for bi- lateral adrenal hyperplasia. In a recent meta-analysis, long-term mortality of patients with PA, independent of subtype, decreased progressively at year 5 and 7 below the level of primary hypertension, an effect even more pronounced in unilateral PA following unilateral adrenalectomy [5].

It has become a tradition for clinicians and researchers to meet every second year in Munich at a conference called "Progress in Primary Aldosteronism”. From October 13 to October 15, 2019 we held the 6th conference at the Carl Friedrich von Siemens Stiftung and celebrated the 10th anniversary with a focus on "New Players on the Block". The primary focus of the meeting remained: to advance the knowledge of PA and to discuss new concepts of diagnosis and treatment. However, at this anniversary the organizers also concentrated on topics and speakers who had not been present in the past. Owing to the special genius loci of the Carl Friedrich von Siemens Foundation at the Nymphenburg castle, and the enthusiasm of more than 100 attending scientists from Europe and overseas, the meeting gave another excellent example of a successful, international, medium-sized disease-oriented symposium.

With the generous support of the Deutsche Forschungsgemeinschaft and the Carl Friedrich von Siemens Stiftung we were able to invite most of the internationally renowned primary aldosteronism experts. The present volume of Hormone and Metabolic Research is 
entirely dedicated to reviews based on PIPA-6 presentations and gives an excellent overview over the current status of the field.

The manuscripts are organized according to their relation to the diagnostic and therapeutic challenges of PA. The study of Gruber and Beuschlein [6] analyses the relevance of hypokalemia as a lead symptom for PA. An important clinical manifestation of PA is atrial fibrillation, as outlined by the study of Pan et al. [7]. A conundrum has been the association between PA and obstructive sleep apnea syndrome, which has recently received quite some attention and is covered in this issue by Pecori et al. [8]. Wannachalee and Turcu [9] review the diagnostic value and pathophysiologic implications of steroid profiles determined by liquid chromatography mass spectrometry, an area which has attracted substantial attention in recent years. Similarly, agonistic angiotensin II type 1 receptor antibodies have become a hot topic in aldosterone research and will be covered by the review article of Meyer et al. [10]. A neglected area of PA research is the regulation of sodium chloride in states of normal and excess aldosterone secretion, as covered by the article by Adolf et al. [11]. Tömböl et al. reviews the evidence for micro RNA as novel markers in the diagnostic work-up of PA [12]. In an original publication, Handgriff et al. analyze the association between glucocorticoid co-secretion, assessed by the $1 \mathrm{mg}$ dexamethasone suppression test, on the prevalence and the time course of thyroid antibodies in PA [13]. In a series of pathophysiologic manuscripts, the role of mast cells [14], expression of aldosterone synthase in adrenalectomy samples [15], the role of aldosterone producing cell clusters [16], and the methodologic advances obtained by tissue mass spectrometry imaging [17] are analyzed. Finally, the study of Gao et al. [18] gives a comprehensive overview on calcium metabolism in PA, followed by an in-depth study on clinical determinants of surgical success by Naruse et al. [19]. The final word and outlook has the nestor of primary aldosteronism research, John Funder, in his commentary "Primary Aldosteronism: Where Are We Now? Where to from Here" [20].

This special issue of Hormone and Metabolic Research gives the interested reader the opportunity to understand where we are, and where our research has to go until the next PIPA meeting. We would like to thank all authors for their valuable contributions to this Special Issue.

Martin Reincke, Felix Beuschlein, and Tracy Ann Williams

\section{Acknowledgements}

We acknowledge the generous support of the Deutsche Forschungsgemeinschaft (T.A.W., F.B., M.R.; CRC/TRR 205/1 “The adrenal gland: Central relay in health and disease"); and the Carl Friedrich von Siemens Stiftung in funding the Progress in Primary Aldosteronism symposion.

\section{Funding}

Additional grant support of the authors of this editorial are: the Else Kröner-Fresenius Stiftung (2013_A182, 2015_A171 and 2019_ A104 to MR) to M.R., the Deutsche Forschungsgemeinschaft to F.B. (BE2177/13-1), and to the European Research Council (grant number 694913 [PAPA] to M.R.).

\section{Conflict of Interest}

The authors declare that they have no conflict of interest.

\section{References}

[1] Yang Y, Reincke M, Williams TA. Prevalence, diagnosis and outcomes of treatment for primary aldosteronism. Best Pract Res Clin Endocrinol Metab 2019, 101365. doi:10.1016/j.beem.2019.101365. [Epub ahead of print]

[2] Mulatero P, Monticone S, Burrello J et al. Guidelines for primary aldosteronism: Uptake by primary care physicians in Europe. J Hypertens 2016; 34: 2253-2257

[3] Jaffe G, Gray Z, Krishnan G et al. Screening rates for primary aldosteronism in resistant. hypertension: A cohort study. Hypertension 2020; 75: 650-659

[4] Monticone S, D’Ascenzo F, Moretti C et al. Cardiovascular events and target organ damage in primary aldosteronism compared with essential hypertension: A systematic review and meta-analysis. Lancet Diabetes Endocrinol 2018; 6: 41-50

[5] Meng Z, Dai Z, Huang K et al. Long-Term mortality for patients of primary aldosteronism compared with essential hypertension: A systematic review and meta-analysis. Front Endocrinol (Lausanne) 2020; 11: 121

[6] Gruber S, Beuschlein F. Hypokalemia and the prevalence of primary aldosteronism. Horm Metab Res 2020; 52: 347-356

[7] Pan C-T, Tsai C-H, Chen Z-W et al. Atrial fibrillation in primary aldosteronism. Horm Metab Res 2020; 52: 357-365

[8] Pecori A, Buffolo F, Pieroni ] et al. Primary aldosteronism and obstructive sleep apnea: casual association or pathophysiological link? Horm Metab Res 2020; 52: 366-372

[9] Wannachalee T, Turcu AF. Developments in primary aldosteronism subtyping using steroid profiling. Horm Metab Res 2020; 52: 373-378

[10] Meyer LS, Gong S, Reincke M et al. Angiotensin II type 1 receptor autoantibodies in primary aldosteronism. Horm Metab Res 2020; 52: 379-385

[11] Adolf C, Schneider H, Heinrich DA et al. Salt appetite and its effects on cardiovascular risk in primary aldosteronism. Horm Metab Res 2020; 52: 386-393

[12] Tömböl Z, Turai PI, Decmann A et al. MicroRNAs and adrenocortical tumors: Where do we stand on primary aldosteronism? Horm Metab Res 2020; 52: 394-403

[13] Handgriff L, Adolf C, Heinrich DA et al. The impact of glucocorticoid co-secretion in primary aldosteronism on thyroid autoantibody titers during the course of disease. Horm Metab Res 2020; 52: 404-411

[14] Lopez A-G, Duparc C, Naccache A et al. Role of mast cells in the control of aldosterone secretion. Horm Metab Res 2020; 52: 412-420

[15] Gomez-Sanchez CE, Gomez-Sanchez EP, Nishimoto K. Immunohistochemistry of the human adrenal CYP11B2 in normal individuals and in patients with primary aldosteronism. Horm Metab Res 2020; 52: 421-426

[16] Lim JS, Rainey WE. The potential role of aldosterone-producing cell clusters in adrenal disease. Horm Metab Res 2020; 52: 427-434

[17] Li F, Feuchtinger A, Walch A et al. In situ metabolite mass spectrometry imaging: New insights into the adrenal gland. Horm Metab Res 2020; 52: 435-447

[18] Gao X, Yamazaki Y, Tezuka Y et al. The effect of extracellular calcium metabolism on aldosterone biosynthesis in physiological and pathological status. Horm Metab Res 2020; 52: 448-453

[19] Naruse M, Yamamoto K, Katabami T et al. Age, gender, and body mass index as determinants of surgical outcome in primary aldosteronism. Horm Metab Res 2020; 52: 454-548

[20] Funder JW. Primary aldosteronism: Where are we now? Where to from here? Horm Metab Res 2020; 52: 459-466 